\title{
A Comprehensive Review of Practical Issues for Interoperability Using the Common Information Model in Smart Grids
}

\author{
Hyun Joong Kim ${ }^{1}$, Chang Min Jeong ${ }^{1}$, Jin-Man Sohn ${ }^{2, *}$, , Jhi-Young Joo ${ }^{3}$, Vaibhav Donde ${ }^{3}$, \\ Youngmi Ko ${ }^{4}$ and Yong Tae Yoon ${ }^{1}$ \\ 1 Department of Electrical and Computer Engineering, Seoul National University, Seoul 08826, Korea; \\ joyfulkkachi@snu.ac.kr (H.J.K.); ckdalsdl311@snu.ac.kr (C.M.J.); ytyoon@snu.ac.kr (Y.T.Y.) \\ 2 Department of Electrical Engineering, Hoseo University, 20, Hoseo-ro 79beon-gil, Baebang-eup, Asan-si, \\ Chungcheongnam-do 31499, Korea \\ 3 Computational Engineering Department, Lawrence Livermore National Laboratory, Livermore, CA 94450, \\ USA; joo3@llnl.gov (J.-Y.J.); donde1@llnl.gov (V.D.) \\ 4 Department of Global Law, Soongsil University, 369, Sangdo-ro, Dongjak-gu, Seoul 06978, Korea; \\ koya21c@ssu.ac.kr \\ * Correspondence: jmsohn@hoseo.edu
}

Received: 30 January 2020; Accepted: 12 March 2020; Published: 19 March 2020

check for updates

\begin{abstract}
Smart grids with interoperability improve grid reliability by collecting system information and transferring it to an energy management system and associated applications through a seamless end-to-end connection. To achieve interoperability, it is required to exchange the semantic information within the different domains. The international electrotechnical commission has established the Common Information Model (CIM) tool, which is a standard application programming interface for the exchange of semantic information in power systems. CIM provides a robust framework for accurate data sharing, merging, and transformation into reusable information. However, as CIM provides a basic framework for information exchange, various practical issues arise in establishing an energy management system capable of exchanging information using CIM. This paper aims to offer a comprehensive understanding by summarizing and categorizing the research on the practical use of CIM for interoperability in smart grids. Many papers are analyzed and the issues are classified into CIM extension, harmonization, and validation to address the issues that arise when establishing an integrated information exchange system.
\end{abstract}

Keywords: interoperability; common information model; IEC 61970; IEC 61968; IEC 61850; model extension; harmonization; validation; application program interface

\section{Introduction}

Interoperability refers to the seamless, end-to-end connectivity of hardware and software in domestic appliances through the transmission and distribution system to the power source, enhancing the coordination of energy flows with real-time flows of information and analysis. The interoperability improves the grid reliability by collecting more useful information and transferring it to the operators and equipment to improve and protect the grid operations [1].

To achieve interoperability in a smart grid, it is required to exchange semantic information within the different domains [2]. The Electric Power Research Institute (EPRI) developed the Common Information Model (CIM) tool, which the International Electrotechnical Commission (IEC) adopted as IEC 61970-301 [3,4]. CIM provides a powerful and flexible integration technology using standard 
application programming interfaces (API). The architecture is fundamentally vendor-neutral, as it is based on open standards $[5,6]$.

CIM can provide a robust framework for accurate information sharing, merging, and transformation into reusable information [5]. The European network of transmission system operators (ENTSO-E) decided to secure the interoperability through information exchange between the transmission system operators by establishing a common grid model exchange specification (CGMES) based on CIM for the exchange of data for power flow, short circuits, and dynamics [7]. The California Independent System Operator (CAISO) aims to create an integrated environment of multiple systems and applications to ensure network reliability and efficiency. A CIM-based business semantic model is proposed to enable the systems and applications to exchange information in a flexible, reusable, and scalable manner [8-11].

Despite the efforts to build interoperable energy management systems (EMS), there are several issues in developing EMS that can exchange information using CIM. In order to address these issues, several research studies and guidelines are proposed [12]. However, there is no paper to provide a summary and comprehensive understanding of these studies. This paper aims to provide a comprehensive understanding for those who are learning CIM for the first time or for those who want to enhance interoperability using CIM by summarizing and organizing solutions for the three issues mentioned above.

The rest of the paper is organized as follows. Section 2 explains how to identify practical issues in establishing interoperability using CIM, such as CIM extension, harmonization, and validation. Section 3 categorizes and summarizes the extended model for various business requirements. Section 4 presents a categorization of approaches for information exchange between CIM and IEC 61850. Section 5 summarizes the research on validation, addressing the efficiency and methodology. The last section reports the discussion and conclusions.

\section{Identification of CIM Practical Issues}

In order to achieve a high level of interoperability for a model-based system, it is necessary to identify challenges that should be overcome in each domain [13]. Zacharewicz et al. [14] classify the challenges into several categories and introduce research and technical limitations to solve them.

According to them, for a new concept it is essential to establish a new model and human resource management as the new business requirements emerge. They also emphasize using a reserve modeling technique to integrate a new model into a legacy system, where the existing model had been verified. Additionally, as the demand for interaction between heterogeneous systems increases, it is argued that a solution for data inconsistency that prevents interaction between them is necessary, which raises the importance of the validation, which determines whether a model-based information system performs its functions based on the business requirements.

In this context, in order to investigate the studies on securing interoperability using CIM in the current smart grid, over 230 studies, which were published before and after the first edition of CIM was released in 2003, were searched using keywords such as interoperability, CIM, IEC 61970, IEC 69168, harmonization, validation, and their combinations in Google Scholar, IEEE Xplore, ReserachGate, and Scopus. Among them, the references cited in this paper include the research published in important journals (e.g., Elsevier indexed journals, IEEE indexed journals) and relevant conferences, the technical report by EPRI, and the international standard documents. The studies are group in three categories according to the challenges for achieving a high level of interoperability, as shown in Figure 1.

The first issue is how to model newly added concepts according to the business requirements and integrate them into the legacy system. Changes in power systems, such as integrating the distributed resources, require new network management systems or changes in legacy applications. In response to these changes, CIM should be extended intermittently to satisfy business requirements. As a standard format, however, CIM describes an information model to reflect the underlying business requirements. For this reason, CIM cannot represent every use case for information exchange [15]. The IEC and EPRI 
have proposed guidelines for designing CIM extension models to reflect the business requirements in development environments [16-18]. In addition, many studies have presented an extension model for specific business requirements. In the following section, by classifying the business requirements into applications for EMS and applications for distribution networks, we summarize the newly designed models and how they are related to the legacy model.

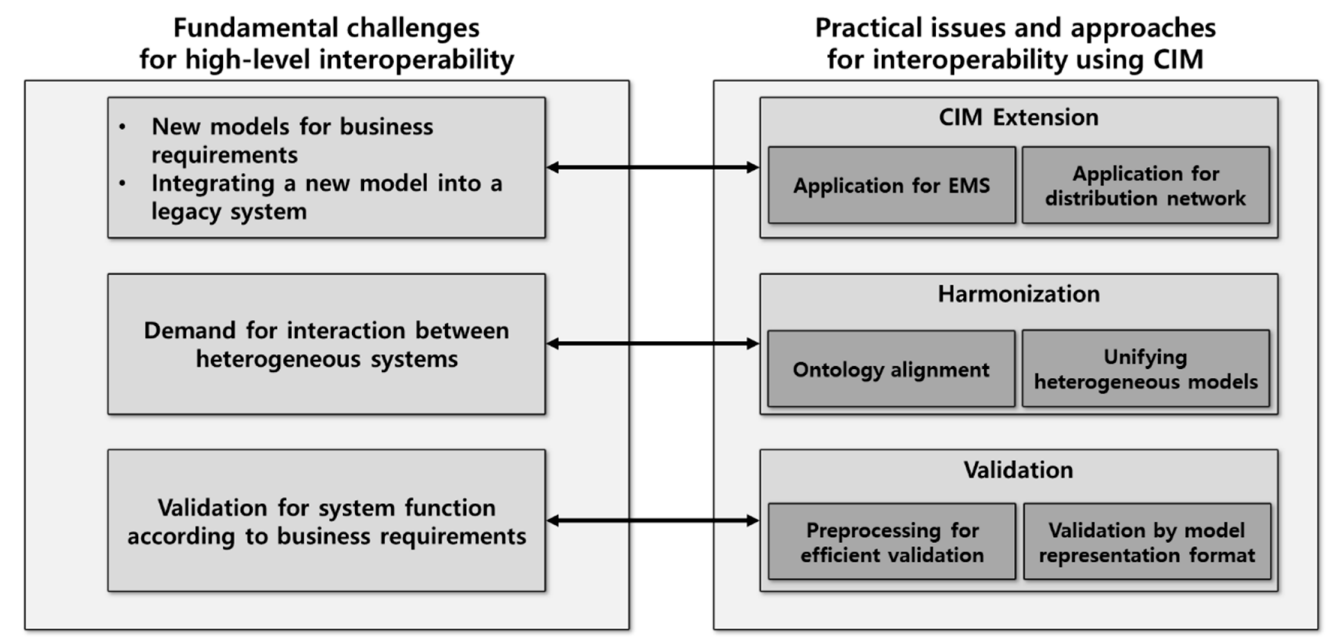

Figure 1. Identifying practical issues and approaches for the Common Information Model (CIM) tool according to fundamental challenges for high-level interoperability. EMS, energy management systems.

The next section is about securing interoperability between heterogeneous systems. According to the National Institute of Standards and Technology (NIST) [19], harmonization is the process of achieving technical equivalency and enabling the interchangeability between different standards with overlapping functionality. A smart grid is an electrical power grid infrastructure with improved efficiency, stability, and safety, using automated control and monitoring based on information and communication technology. CIM and IEC 61850 are essential standards for building energy management systems and automation substation systems, respectively, by providing a key information model [20]. Although the two standards focus on overlapping domains, they are developed independently; thus, the information exchange between the systems based on the two standards is incompatible. As interfaces for information exchange between systems based on different standards are needed, the IEC and EPRI have provided guidelines for establishing the data interfaces between the two standards [21-24]. Many studies have also suggested solutions. Based on the methodology for setting an interface between heterogeneous systems, the guidelines and solutions can be classified into the ontology alignment approach and unified modeling. In Section 4, we organized their characteristics.

Lastly, the validation determines whether exchanged information conforms to an information model. Information exchange using CIM is performed through message instances by applications or system participants using profiles or subsets of CIM for application use cases [25]. However, due to the lack of information synchronization between the system participants, message specification could easily cause interface differences and further impede the information sharing and interoperation between the CIM applications. Validation for the message specifications is vital and essential for the implementation of multi-system, multi-service, and multi-objective enterprise-level integration [26]. By analyzing the preprocessing methods for effective validation and the validation concept according to the format in which the model was represented, we summarize the interoperability verification methods using CIM.

\section{CIM Extension}

In this section, we analyze the trend in academic research of new extended models emerging as new business requirements emerge. 
At the early stage of development, CIM was modeled based on the system analysis function of the EMS in generation and transmission domains. This function includes the basic EMS applications, such as topology processing, state estimation, and power flow. The applications are modeled, which are executed based on per phase analysis and the bus-branch model. After edition 3 of IEC 61970-301, packages for contingency, operational limits, network reduction, and diagrams were supplemented in order to integrate the model for new EMS applications and enhance the function of legacy applications.

The distribution network is undergoing change due to the integration of distributed resources, utilizing consumer data using smart meters, asset management, and human resource management. Support is required for the integration of distribution management system (DMS) applications that have different interfaces and run-time environments [27]. After the second edition of standard CIM, models for distribution networks, such as unbalanced three-phase analysis, and distributed resources were included in standard CIM. On the other hand, models for assets and human resources in distributed networks have been ratified as IEC 61968-11.

In this context, the paper classifies the CIM extensions into the extension for EMS applications and the extension for the distribution network, according to the domain to which the applications belong. In addition, the relation between the extended model and the standard CIM is deduced in the order of revision of the standard CIM, as shown in the Table 1.

\subsection{Extension for EMS Application}

\subsubsection{Topology Processing}

As the bus-branch model is used to analyze the power flow in EMS, the bus-branch model needs to be converted from the node-breaker model, which is used to describe the connectivity between the ConductingEquipment class in CIM. In the conversion process, as the number of the ConnectivityNode classes in the node-breaker model increases, the process takes longer. Popvic et al. [28] proposed a grouping using containers, such as the bay class in CIM, and an algorithm using these to shorten the processing time. By adding a new association that references itself, it is possible to reduce the processing time by grouping the conducting equipment classes and the connectivity node classes [29]. To use the bus-branch model in CIM for convenient power system analysis, Pradeep et al. [30] extended the topology model to exchange the conducting equipment class information efficiently by adding a TopologicalBranch class, which may have no association or many associations, to the TopologicalNode class. Huang et al. [31] proposed an algorithm to figure out a TopologicalIsland class in systems containing distributed resources.

\subsubsection{Network Reduction and Equipment}

When the internal network is connected to an external network, the EMS expresses the external network as an equivalent model to grasp the influence on the internal system caused by faults from the external network. In particular, it is important to prepare a contingency for the internal system in the case of failure of the external network.

Sun et al. [32] proposed an extended CIM for an equivalent network to guarantee the accuracy of online protective relay setting and short circuit capacity from short circuit analysis, including external networks. To conduct short circuit analysis, a negative sequence impedance of equipment branches are required, such as the ACLineSegement class and the PowerTransformer class. However, even though the equivalent package was supplemented in the third edition of the standard CIM, the negative sequence impedance was not considered for faults; it was added to the package in the sixth edition [16].

When equipment is not defined in the standard CIM, the most common method of defining the equipment in the extended model is adding an inherited class [33]. On the other hand, as various types of switches exist in the distribution network, a study was performed to expand the model by adding an enumeration to represent a switch [34]. 


\subsubsection{State Estimation}

The state estimation is a core EMS application for ensuring accurate power system operation. It is a fundamental function for filtering out the noise from the metered values and obtaining the state values, which are the closest to actual values, by using statistical methods.

Using the topology and measurement information in CIM, $\mathrm{Xu}$ et al. [35] suggested an extended model that defines state variables, noise values, and errors. Qin et al. [36] extended CIM to express the results of three-phase state estimation using the linear relationship between the branch currents and the load currents. However, in the fourth edition of 61960-301 [37], the state variables package was added to express the results of the power system analysis using the bus-branch model. Sharma et al. [38] complemented CIM for state estimation in multiple areas by adding a class that has the covariance values of the state variables and relations to the svVoltage class in the state variables package.

\subsubsection{Single Line Diagram}

The graphical interface aims to visualize the data for power system management. The single line diagram is the most common data visualization method for representing the connectivity and status information of power system equipment. Many methodologies and algorithms have been proposed for generating network and substation diagrams.

However, most of them have been restricted for wide use, as they are designed for certain data and models, which causes interoperability problems between the applications that handle diagrams in the EMS. In order to solve this problem, IEC 61970-453, which defines a diagram layout profile based on scalable vector graphics, was published in 2008 , and the diagram package was established in the second edition of IEC 61970-301 in 2014.

Ten et al. [39] presented a framework for automatically generating diagram information in the supervisory control and data acquisition system (SCADA) from topology and geographical data. Ravikumar et al. [40] proposed an extended model providing various layouts and views for user-friendly interfaces and a relative coordination system for solving re-alignment problems in network diagrams when editing or merging the graphics. Hussain et al. [41] proposed a technique for auto-drawing single-line diagrams for multivendor distribution systems using CIM.

\subsubsection{Model Authority}

It is difficult to exchange information between the different systems or applications when they have their own identification schemes for the same power system resources and objects. Ravikumar et al. $[42,43]$ proposed an extended model to separate and manage the identification schemes of different systems or applications by introducing the ModelAuthorityContainer class, which gives authority to the power system resources.

\subsubsection{Dynamic Rating}

The static operational ratings for power system equipment are defined as an attribute of the device class. Since IEC 61970-301 Ed3 was proposed in 2011, the OperationalLimits class has been added so that the rating information can be extended without changing the model. However, the operational rating of the power system equipment can vary depending on the external environment, for example with temperature and moisture; thus, it is named dynamic rating. Moseley et al. [44] suggested how to represent the dynamic rating using CIM for some cases, such as when the dynamic rating is provided by the system operator through SCADA.

\subsubsection{Online Monitoring}

The SCADA package in the CIM maintains the basic structure and function for a long time. Cheng and Zhou [45] mentioned that as many vendors provide their own designed systems for utility requirements, it is hard to build a system for visualizing and managing power system resources using 
CIM. For this reason, the authors suggested a new class, which is related to the substation and line, and a subclass according to the functionality required by the monitoring system.

\subsubsection{Business Process}

CIM is a model expressed in the unified modeling language (UML) to describe electrical power market and power system resources of transmission and distribution networks. Many utilities adopt CIM for secure interoperability. However, CIM is not suitable for representing a chronological process, such as market bidding. In order to overcome this limitation, Chandramohan et al. [46] suggested using a business process modeling notation standard to extract a profile, a subset of the model, as it is much more efficient for obtaining a profile as compared to the CIM activity diagram, which is typically used for the representation process.

Ravikumar et al. [47] proposed an extended model that integrates the process ontology model with CIM to represent utility business process as a standard process model for solution of interoperability problem between different systems. The extended model defines a PowerSystemProcess class and a Process artifact, which represents a whole process and a part of the process, respectively, similar to the association between the EquipmentContainer class and the Equipment class in CIM.

\subsection{Extension for Distribution Network}

\subsubsection{Distributed Generation}

In the early days, CIM did not consider distributed generation using renewable resources. However, Ding et al. [48] proposed an extension model for the EMS function of distributed resources. This paper proposed an extended model by defining a subclass of the GeneratingUnit class for a wind power plant, a photovoltaic generator, a battery, and fuel cells. However, the GeneratingUnit class is defined as a device that provides an AC current by converting kinetic energy into electrical energy. Therefore, the modeling of power generation sources using power electronics units, such as a photovoltaic generator, a battery, and a fuel cell, showed a limitation in including the characteristics of power electronics.

Energy storage devices can increase the availability of renewable resources by providing ancillary balancing services for the uncertainty of renewable resources. Hargreaves et al. [49] classified the energy storage devices that can be connected to power systems through energy storage methods. In addition, the paper defined the energy storage unit as a refinement of the RegulatingCondEq class.

As the energy storage devices do not have any rotational machinery but have chemical and electronics characteristics, Zhao and Liu [50] showed that modeling energy storage is independent of the GeneartingUnit class. This modeling concept was reflected in CIM Ed.6.0 [16]. In the case of the WindGeneratingUnit class, which converts kinetic energy into electrical energy through a turbine, it was defined as a class type that inherits the GeneratingUnit class. Huang et al. [51] presented a model of a wind generator that can be automatically dispatched based on these characteristics.

However, devices connected to the grid using power electronics facilities, such as the photovoltaic, battery, and power electronics wind units, are defined as the PowerElectronicsUnit class, rather than subunits of the GeneratingUnit class, which uses turbines.

\subsubsection{Meter Management}

Vukmirovic and Erdeljan [52] proposed the need for a virtual meter for managing multiple meter data in a smart grid environment and designed a model by establishing the association with multiple meters. IEC 61968-11 Ed.2.0 [53] proposed a generalized meter model to accommodate the virtual meters. 
Table 1. CIM extension overview. HVDC, High-Voltage Direct Current.

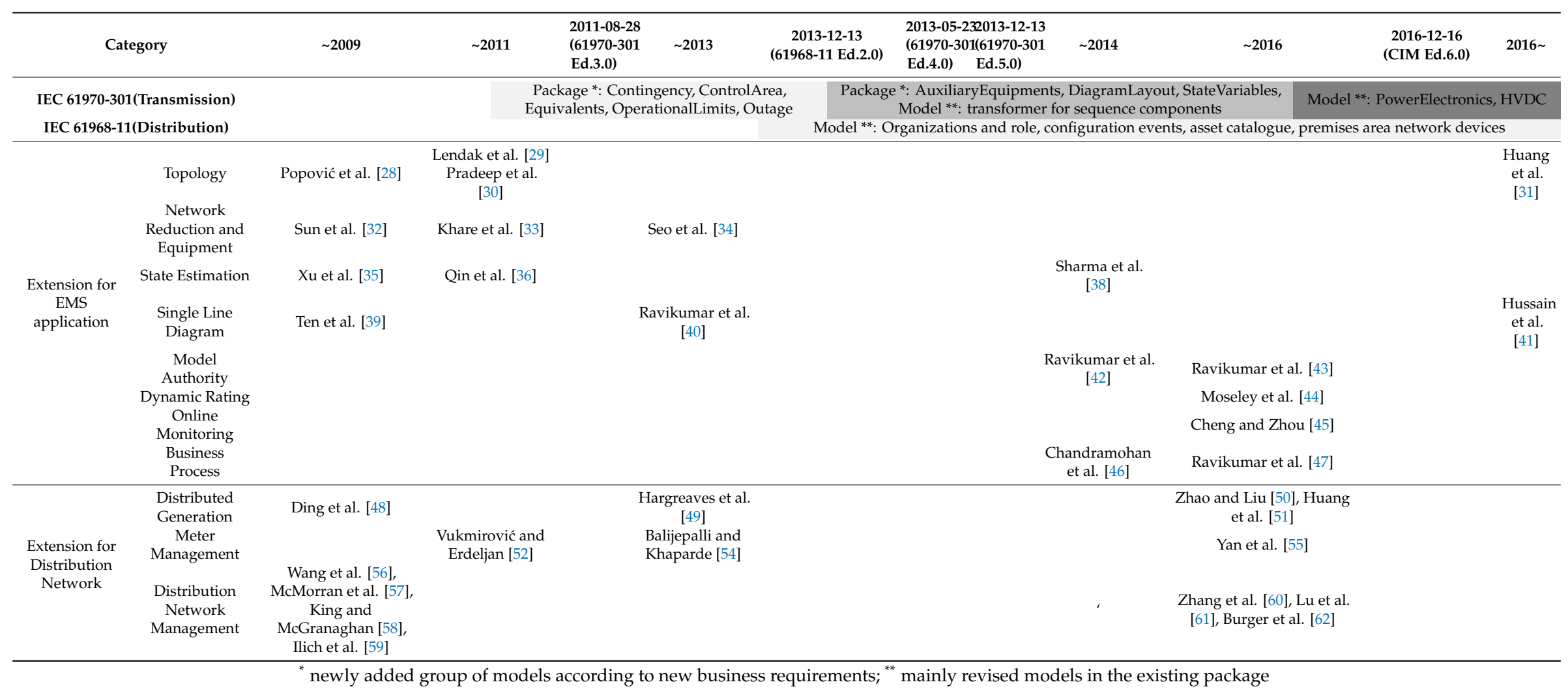


Balijepalli and Khaparde [54] extended the green button standard for domestic energy consumption data and utility functions to utilize and manage them in CIM. This paper did not simply entirely absorb the green button model into CIM but presented the model in a number of major packages and subordinate forms, reflecting the semantic characteristics of the existing CIM.

A demand response has emerged as an important application for distribution networks with the development of information and communication technologies. However, the demand response model defined in IEC 61968-11 Ed.2.0 [53] was very abstract and simple. Yan et al. [55] fully or partially adopted the functions of the Domain, Core, LoadModel, and Common packages of CIM, along with the Customer, Metering, LoadControl, and PaymentMetering packages of IEC 61968-11, to express the open automated demand response (OpenADR) that defines the data standard for CIM.

\subsubsection{Distribution Network Management}

Wang et al. [56] proposed a model for three-phase unbalanced power flow analysis by adding multiphase characteristics to the existing connectivity model for the three-phase network configuration, instead of a single phase Additionally, the feeder model, the most important model in power distribution, is presented through the whole-part relation. In IEC 61970-301 Ed.6.0 [16], the feeder model is represented in a similar fashion.

In addition, a power distribution system requires many applications for DMS, such as asset management for multiple equipment. McMorran et al. [57] proposed an extension of the model of distribution assets, while Tower, King, and McGranaghan [58] suggested the need for a model for applications such as asset management, fault location, and power monitoring. In [59], CIM was used as the single common repository for asset management and network modeling.

Zhang et al. [60] proposed a model for distribution network asset management. In particular, this paper proposed a physical model that constructs a distribution network by adding associations with cables, rather than simply structures of cables and poles. One of the main applications included in DMS is outage prediction. Lu et al. [61] suggested an extension model where outage prediction data was added as an attribute by adding refinement for each piece of equipment to the AssetInfo package.

In addition, Burger et al. [62] proposed a data model for outage management in CIM through cooperation with IEC 61850 and other systems, designed according to companion specification for energy metering (COSEM).

\section{Harmonization}

Harmonization is the process of enabling interchangeability between different systems designed by different information models with overlapping functionality. It requires an architecture that leads key points of interoperability and associated interfaces between heterogeneous systems built by different information models [63]. To establish the architecture, many studies suggest a solution for harmonization of CIM and IEC 61850. The EPRI has proposed underlying methodologies and the IEC has set up the standard guidelines IEC 62361-102 and IEC 61968-14 [21-24].

However, as it is necessary to clarify model differences between the two different standards [20], it is challenging for the researchers, who would not have expertise in both of them, to follow up the research with harmonization. In addition, no educational materials provide a comprehensive understanding of harmonization. In this section, we summarize the papers and reports and classify them into ontology approaches and unified modeling based on the taxonomy suggested by Nieves et al. [64], as shown in the Table 2. 
Table 2. Trends of harmonization based on methodology. EPRI, Electric Power Research Institute; IEC, International Electrotechnical Commission; NAESB, North American Energy Standards Board.

\begin{tabular}{|c|c|c|c|c|c|}
\hline $\mathrm{Me}$ & odology & $\sim 2005$ & $\sim 2010$ & $\sim 2015$ & $\sim 2018$ \\
\hline \multirow{4}{*}{$\begin{array}{l}\text { Ontology } \\
\text { Approach }\end{array}$} & $\begin{array}{l}\text { Mapping the } \\
\text { Objects }\end{array}$ & $\begin{array}{c}\text { Kostic et al. } \\
{[65]}\end{array}$ & $\begin{array}{l}\text { Pradeep et al. [66], } \\
\text { Choi et al. [67] }\end{array}$ & $\begin{array}{l}\text { Naumann et al. [68], } \\
\text { IEC 61968-14 [23] }\end{array}$ & \multirow{4}{*}{ Kim et al. [74] } \\
\hline & & & & Santodomingo et al. [70], & \\
\hline & Ontology & & Santodomingo et al. & Santodomingo et al. [71], & \\
\hline & Matching & & [69] & $\begin{array}{l}\text { Santodomingo et al. [72], } \\
\text { Zhang and Wang [73] }\end{array}$ & \\
\hline \multirow{8}{*}{$\begin{array}{c}\text { Unified } \\
\text { Modeling }\end{array}$} & & & \multirow{5}{*}{$\begin{array}{c}\text { Preiss and Kostić } \\
\text { [76], } \\
\text { EPRI [21], } \\
\text { EPRI [22], } \\
\text { Mercurio et al. [77] }\end{array}$} & & Pei et al. [80], \\
\hline & & & & & NAESB [81], \\
\hline & Mapping and & Kostic et al. & & Dutta and Kezunovic [78], & Schumilin et al. [82], \\
\hline & Extension & [75] & & Sun et al. [79] & Schumilin et al. [83], \\
\hline & & & & & $\begin{array}{c}\text { IEC 62361-102 [24], } \\
\text { Alaerjan et al. [84] }\end{array}$ \\
\hline & \multirow{3}{*}{ Meta-Modeling } & & & Kim et al. [85], & \multirow{3}{*}{ Lee and Kim [88] } \\
\hline & & & & Kim et al. [86], & \\
\hline & & & & $\begin{array}{l}\text { Lee et al. [87], } \\
\text { Jiaan et al. [89] }\end{array}$ & \\
\hline
\end{tabular}

\subsection{Ontology approach}

According to Nieves et al. [64], "A knowledge model is a way to abstract the disparate data and information. It helps us to understand how different pieces of information relate to each other. A semantic model is a kind of knowledge model. The semantic model consists of a network of concepts and the relationships between those concepts. Concepts are a particular idea or topic with which the user is concerned. In general terms, the concepts and relationships together are often known as an ontology."

For example, CIM is a semantic model expressed in UML for describing physical, electrical, and data elements that constitute a power system. Ontology can be considered as a class, an attribute of the class, and the relationship between the class and another class.

The aim of the ontology-based approach in the harmonization between the EMS of a control center using CIM and a substation using IEC 61850 is to find the corresponding element that has the same meaning between the two information models and exchange data based on the corresponding ontology. This paper classifies the ontology approach into the mapping method and the ontology matching method, and summarizes the related research.

\subsubsection{Mapping the objects of CIM and IEC 61850}

Kostic et al. [65] suggested three scenarios for the exchange of information between a substation and a control center. The first is that information exchange can be automated, even if the API for harmonization of each system is not fully implemented.

In the second scenario, a method of exchanging dynamic information can be carried out by integrating the protocols through conversion between the two systems. The last scenario is where information exchanges only when necessary, such as a topology change, through CIM extensible markup language (XML).

Pradeep et al. [66] selected a method for mapping the static data considering the corresponding elements of two systems and allocating the dynamic data at the elements. However, this mapping method can be a problem in bidirectional information exchange as there is a limit to expressing semantic data, as the connectivity node class, the terminal of the busbar class, and the busbar class of the CIM are mapped to the connectivity node of the IEC 61850.

Choi et al. [67] suggested a method to transform a single line diagram representing a substation configuration into a CIM for mapping between two system models. After the transformation, mapping was performed considering components, containment, and interconnection between two models. This method is an effective way to maintain correspondence between the elements of two models. 
The mapping method in Naumann et al. [68] is applied to the exchange measurement data for automated protection work applications. The measurement data contains not only analog or discrete values, but also information such as a timestamp for those values. Since CIM and IEC 61850 have their own data structures, the semantic characteristics are considered in this method.

Multispeak defines a standardized data interface between the applications used by the utility. IEC 61968-14 suggested a way to map each element from CIM to multispeak using the XML mapping tool, and provides guidelines and practical examples for application interoperability through the enterprise service bus (ESB) [23].

The mapping objects method between two standards is useful for point-to-point information exchange. However, this method does not consider the complex semantics of the two standards, such as the relationship for connectivity. Thus, it is likely to cause a mismatch during mapping of the objects and has a limitation in handling the semantic hierarchy.

\subsubsection{Ontology Matching}

The mapping method mentioned above analyzes the correspondence between two standards manually and performs data mapping according to the correspondence. Ontology matching is used to seek the correspondence between two information models, but the most significant difference is that it is executed by using software tools. Ontology matching can be defined as the process of finding and processing semantic correspondence between the objects of different standards. Therefore, harmonization between CIM and IEC 61850 can be considered as an ontology matching problem [69].

Santodomingo et al. [69] designed a methodology for ontology matching and implemented it through an ontology matching program called electric system ontologies data translator (ESODAT). The authors extracted a profile for information exchange from the information model of each system and then performed alignments to identify correspondence with each other using profiles extracted in the form of web ontology language (OWL). Based on the alignments, a conversion between the instance files containing information from CIM and IEC 61850 is performed. However, it is not likely to convert information accurately when the information represents complicated relations at the class level. In order to alleviate complexity, an additional tool needs to be used.

Santodomingo et al. [70] suggested a more sophisticated and automatic method for ontology alignment between the two models. In this study, the authors designed an ontology alignment approach using a string-distance-based, lexicon-based, structure-based, and specific domain-knowledge-based algorithm, and carried this out it with software tools such as CIMMappingBench and ESODAT.

Santodomingo et al. [71] utilized the upgraded ESODAT to automate the entire ontology matching process, which reduced the supplement process for performing alignment due to complex semantic expressions in previous papers.

Santodomingo et al. [72] solved the problem whereby ontology matching could only be implemented in static data due to the heterogeneity of dynamic and static data in IEC 61850. Thus, a method for the exchange of dynamic data was proposed by performing ontology matching between the dynamic data of IEC 61850 and the measurement of CIM.

Zhang and Wang [73] set up an algorithm for semantic mapping of two standard models in ontology alignment. In the first step, the algorithm determines the similarity using the names, comments, and labels of the elements of the two standards. In the second step, the authors use the graph matching method to define the relationships between elements in each model. Lastly, they define the correspondence and relationships between elements. In addition, they implemented the automated conversion substation configuration language (SCL) file to $\mathrm{XML}$, which is the message instance file language for IEC 61850 and CIM.

Kim et al. [74] employed a similar ontology matching method to convert SCL message instances into XML, in which CIM is extended for distributed resources defined in IEC 61850 for microgrid operation.

The outstanding characteristic of ontology matching involves reduce human error by automating the process, unlike the mapping method, because software tools are executed by a semantic alignment 
algorithm. In addition, the accuracy of the alignments has been improved with the evolution of the algorithm and tools for semantic matching.

\subsection{Unified Modeling}

The other approach for harmonization between CIM and IEC 61850 is to set up a unified model integrating two information models. The output files, which have information in the form of a message file, such as XML or SCL, can be exchanged through a middleware. In this section, research is classified according to the method of unifying the two information models. One method is the mapping and extension method, which finds the corresponding elements of two models and makes additional models for mismatch through semantic analysis of two different models. The other method is a meta-modeling approach, providing a model-based guideline for integrating two different models.

\subsubsection{Mapping and Extension}

Kostic et al. [75] proposed a message-based data exchange method between two systems by extracting the substation configuration file and converting it to a resource description framework (RDF), representing ontology. The unified model for the two systems was set up in UML to maintain the semantics of the data object between the two system models. This method uses the extension model of CIM, including mapping of common entities of two system models. However, the model should be modified as each system model changes.

Preiss and Kostic [76] argued that all modules dealing with data should have the same model for data types and the same relationships for harmonization. For this reason, the authors suggested criteria for establishing a unified model. The criteria include not only a simple mapping method but also a guideline to deal with incompatibility or inconsistency between two different system models, which help to solve the problem of data redundancy.

The EPRI analyzed major use cases for harmonization between two heterogeneous systems and suggested several guidelines. These guidelines described an obvious way to design unified models for equipment monitoring, network operations, asset management, geographic location, protection schemes, and other applications, using mapping and CIM extension if necessary [21,22].

Mercurio et al. [77] used the CIM extension, including IEC 61850, to set up a unified model. Based on the unified model, data exchange was performed using web services, which are developed for interaction between different systems as middleware. However, there may be overlapping semantics between extension and CIM.

Dutta and Kezunovic [78] proposed a unified model to exchange information between the control center and the substation, with a profile that contains the application's functions for fault applications. In order to set up the model, the authors use the mapping and extension method.

Sun et al. [79] pointed out that it is inefficient to build a unified model that includes all of the substation models because each substation has its model for a particular business requirement. Therefore, the authors suggested the distributed modeling method, where the adaptive model is extracted from the substation and transmitted to the EMS for the necessary functions, such as state estimation.

Pei et al. [80] proposed a unified CIM model that includes information from IEC 61850 for the application functions required by the control center, such as the microgrid battery operation.

The Open Field Message Bus (OpenFMB) is a framework for interoperability in power distribution networks that enables devices in a power distribution network to interact with each other using general local connectivity and local peer-to-peer communication. It adopted many data standards, including CIM and IEC 61850, to establish a unified model and was ratified by the North American Energy Standards Board (NAESB). This model supports message-based information exchange [81].

Schumilin et al. [82] introduced harmonization using the CIM extension, which contains the measurement data and time-series data defined in IEC 61850. In order to represent a pair of corresponding elements between the two models, a new class is introduced at the point of integration. 
The authors also employed CIM as a semantic middleware layer for data access, because it is wide enough to cover IEC 61850 and is suited as a mediator [83].

IEC 62361-102 provided an effective way of exchanging information between the two standards through the use cases that preferentially require harmonization between CIM and IEC 61850. This method uses semantic mapping between two information models and extends CIM if necessary [24].

Alaerjan et al. [84] designed a unified model between the two standards using mapping and extension methods. Based on the model, the authors demonstrated an architecture for data exchange using a network communication middleware called data distribution service (DDS). The architecture for DDS can exchange information between systems using different communication protocols.

The mapping and extension method is the most common method for building an integration model and has also been considered for use recently. However, as the standard evolves, the integration model also needs to be modified.

\subsubsection{Meta-Modeling}

A meta-model is a model of a model. For example, UML is a meta model for describing the CIM. By using the meta-modeling method, it is effective to set up a semantic model that considers data inconsistency problems. Kim et al. [85] suggested a meta-modeling method for establishing a unified model for dynamic data.

In a follow-up study, Kim et al. [86] designed a unified model based on the meta-modeling method and demonstrated the conversion of instance files of the two standards for information exchange using the query, view, and transformation (QVT) software tool.

Lee et al. [87] argued that one of the most important considerations in establishing a unified model is to ensure the consistency of the data type defined in each standard. For this reason, the authors proposed a method for integrating the data types into a unified model concerning semantical consistency.

However, when setting up a unified model through meta-modeling, there is a limitation to reflecting semantic information with complex relationships, such as electrical connectivity. Lee and Kim [88] designed a unified model with the meta-modeling method, in which the connectivity of each standard can be handled.

Jiaan et al. [89] presented a method to establish a unified model that reflects the needs of many participants in a smart grid. The authors adopt a chart modeling method that allows each participant to build a model cooperatively. Although the specific model was not provided, it is classified as meta-modeling because it presents a technique to set up a unified model.

The mapping and extension method requires manual analysis in the process of integrating the two standards. Therefore, it is necessary to consider the loss of semantic properties that can occur due to human error. The meta-modeling approach could be a new solution to overcome the consideration of the mapping and extension method by establishing a fundamental guideline for merging the different models.

\section{Validation}

Validation or verification is the process of validating that each application or system entity properly configured the profile and instance by complying with the standard determined for interoperability. This process is essential and important for interoperability. There is a growing need to validate information that will be exchanged between and inside applications or entities in the power system industry in the future because many different components will be linked in the system. In this situation, data that needs to be validated will increase, so data preprocessing is important for more efficient validation. In addition, the various methods exist for validation are divided into XML, RDF, and UML validation methods, according to the model type or schema used for validation in this paper. CIM data preprocessing for efficient validation will be presented in Section 5.1. The validation methods for XML, RDF, and UML will be discussed in Section 5.2. 


\subsection{CIM Data Preprocessing for Validation}

The power system is a huge system that consists of many components. Therefore, there are a lot of data to be exchanged. For interoperability, these data should be validated and the process of validation should not take much time. Therefore, the data to be validated should be minimized or processed before for more efficient validation.

Huang and Nair [90] explained how to select and send only necessary parts rather than sending and receiving all system data, as before. Based on the criteria set by authors for profiles, functional characteristics were selected and classified into static data and dynamic data, and only the dynamic data that continuously changed was used for the exchange to minimize the validation.

Ravikumar et al. [25] distinguished profiles into component viewpoint (CVP) and application viewpoint (AVP) profiles, considering that the production of profiles for validation is highly influenced by the CIM version and the type of application. This allows them to create profiles faster and be less susceptible to ever-changing CIM.

Deng et al. [91] tried to improve validation in a different way from the above two papers. By applying parallel K-means clustering using the Aliyun cloud platform, analysis he data verification calculation time was reduced and accuracy was improved.

\subsection{Model Schema Validation}

In this section, we will look at papers related to actual validation. In this paper, $\mathrm{XML}, \mathrm{RDF}$, and UML validation are classified according to the model type or schema used for validation. CIM has a RDF structure, can be written in XML format, and can also be expressed in UML, so that these three models can be used for validation. XML is a multipurpose markup language developed by the World Wide Web Consortium (W3C) and is recommended for use in creating other markup languages. RDF is a standard for expressing resource information on the web. It is proposed by the W3C and uses XML as the descriptive term. UML is a modeling language used to express program design and is used for various purposes. Table 3 summarizes related papers.

Table 3. Validation based on model schema. XML, extensible markup language; RDF, resource description framework; UML, unified modeling language.

\begin{tabular}{ccccc}
\hline Model Schema & $\sim 2010$ & $\sim 2013$ & $\sim 2016$ & $\sim 2019$ \\
\hline XML & Hallé et al. [92] & Yu et al. [26] & Zhang et al. [93] & Tomaszuk, \\
RDF & & & & Dominik [95] \\
& & Dangi et al. [94] & & Nenadić et al. [96] \\
UML & & Marcadet and & Jang et al. [98] \\
& & & Lambert [97] & Jang et al. [99] \\
\hline
\end{tabular}

\subsubsection{XML Validation}

Hallé et al. [92] extracted a tree structure from the Netconf, which is a network protocol defined by Internet Engineering Task Force, and suggested the method to enable not only simple syntax checking but also semantic dependency validation based on an XML-based logical method and tree query logic.

$\mathrm{Yu}$ et al. [26] proposed an XML specification; that is, XML validation, which performs interoperability based on IEC standards and guarantees information exchange.

Zhang et al. [93] analyzed the interoperability model currently in use and proposed an interoperability test that enables file format validation, CIM compliance verification, and model validation. 


\subsubsection{RDF Validation}

Dangi et al. [94] presented semantic modeling for harmonizing hundreds of smart grid standards and presented a method to convert UML into OWL, which is machine-readable for validation. Through this, it became possible to validate even the parts that were difficult to validate in UML.

Tomaszuk and Dominik [95] summarized the requirements of RDF validation, which had been studied in the academic world up to that time, and classified the RDF validation language used for validation. In addition, it divided RDF constraint expression into data definition language (DDL) using a relational database and document type definition (DTD) using XML documents.

Nenadić et al. [96] presented a validation method through shapes constraint language (SHACL), which is an RDF validation language based on CIM RDF schema, and derived requirements for it.

\subsubsection{UML validation}

Marcadet and Lambert [97] divided validation into syntactic validation and semantic validation. It pointed out that UML is used at the semantic level of CIM and XML is used at the syntactic level of CIM, however validation of both levels is mainly based on XML. In order to perform semantic level validation expressed in UML (that is, semantic validation), it was insisted that UML itself should be validated using a model-level validation program, such as RiseClipse.

Jang et al. [98] presented a novel validation algorithm, which is different from the existing XML-based SCL validation, which only allows schema validation and information model validation. This algorithm is capable of Institution of Engineering and Technology (IET) consistency validation, comma-separated values (CSV) of online intelligent electronic device (IED) consistency validation, utility communication architecture-international users group (UCA-IUG) procedure validation, and user-defined rule validation, and has the ability to search for errors, enabling more flexible digital substation operation.

Jang et al. [99] pointed out that the current data model standardization consists of a text-based table format, which cannot solve duplication problems. Therefore, this paper proposed rule-based validation based on the UML model to solve this problem.

\section{Discussion and Conclusion}

Information exchange interface design is vital for establishing interoperability in smart grids to collect and exchange data between the EMS and applications. CIM provides a semantic data model for establishing a data exchange interface. Some countries decided to develop EMS with interoperability using CIM. However, there are some practical issues during system development. This paper selects three issues by analyzing standard documents, institutional reports, and multiple research papers, and the approaches for each issue are summarized as follows.

The first issue is the CIM extension. The API provided by the standard CIM represents the most basic semantic information model. However, various business requirements arise as power network changes. These require the CIM extension to enhance the information model, which is not provided by the standard CIM. We analyze the research related to model expansion and classify it into extension models for EMS applications and extension models for distribution networks.

Applications for extensions are involved in detailing and efficiency for important functions of EMS. Many studies on securing efficient EMS operation have analyzed and categorized functions into topology processing, state estimation, and network reduction and equipment. The specific EMS functions are summarized through classification into a single-line diagram, model authority, online monitoring, and business processes.

An extended model for distribution networks for metering management and distribution network management uses simple extension methods, some of which are shown in IEC 61968-11. However, the model for the distributed generation and feeder is accepted in IEC 61970-301, not IEC 61968-11. The distributed generator is merged into the Generation package in CIM. In consideration of mechanical 
characteristics, some of the distributed generators using power electronics instruments are modeled independently from the GeneratingUnit class. In the case of the feeder model, it is shown in the Core package, similar to the EquipmentContainer class.

The second issue is harmonization. An information exchange with different systems and applications developed based on different standards is required for robust power system operation. Harmonization between the two standards involves the establishment of an information exchange interface for different standards-based systems and applications. This study classifies harmonization approaches into ontology approaches and unified modeling by analyzing the characteristics of each solution.

Ontology approaches can be divided into the mapping method and ontology matching method. The mapping method exchanges information through a mapping table between data defined in two standards at the point where information exchange is needed. This approach is straightforward and quick to implement but suffers from human error and the inability to automate. Ontology matching, on the other hand, uses semantic analysis tools to analyze the semantic ontology of two information models and exchange information based on the results. It was deduced that research has recently been conducted more for this approach more so than for the mapping method because the tools are more improved and able to function automatically.

The unified modeling method establishes a data model that integrates two standard information models. Information can be exchanged between systems designed by different standards using middleware or a message bus. Mapping and extension methods have been used in the past. The EPRI established underlying harmonization guidelines and the IEC also applied this method to the standard. The other unified modeling technique is meta-modeling. A meta-model is a model that can express the model. That is, UML for expressing CIM is the meta-model. This method has the advantage of providing a systematic guide for establishing an integrated model of the two standards.

The third issue is validation. This is the process of judging whether a model instance, which is created by a system or application for information exchange, conforms to the profile or information model agreed upon within the smart grid. It is difficult for students or beginners to learn validation processes and use validation tools because training is usually delivered through an organization, such as CIM user groups and commercial tool vendors. This paper introduces the preprocessing methods for efficient validation and validation methods according to the model expression language.

The contribution of this study is to classify issues such as model extension, harmonization, and validation, which can occur when securing interoperability through information exchange using CIM in EMS. It also offers a comprehensive understanding for CIM users by categorizing the solution for each issue.

Author Contributions: Conceptualization, H.J.K. and J.-M.S.; methodology, H.J.K. and J.-M.S.; formal analysis, H.J.K., C.M.J. and J.-M.S.; investigation, H.J.K., C.M.J. and J.-M.S.; writing-original draft preparation, H.J.K., C.M.J. and J.-M.S.; writing — review and editing, J.-Y.J., V.D. and Y.K.; visualization, H.J.K. and C.M.J.; supervision, J.-M.S.; funding acquisition, Y.T.Y. All authors have read and agreed to the published version of the manuscript.

Funding: This research was funded by Korea Institute of Energy Technology Evaluation and planning, grant number 0668-20190244.

Acknowledgments: The authors gratefully acknowledge that this work performed under the auspices of the U.S. Department of Energy by Lawrence Livermore National Laboratory under Contract DE-AC52-07NA27344.

Conflicts of Interest: The authors declare no conflict of interest.

\section{References}

1. GridWise Architecture Council, Policy Team. Introduction to Interoperability and Decision-Makers Interoperability Checklist version 1.5. 2010. Available online: https://www.gridwiseac.org/pdfs/gwac decisionmakerchecklist_v1_5.pdf (accessed on 22 January 2020).

2. Kim, D.-K.; Alaerjan, A.; Lu, L.; Yang, H.; Jang, H. Toward Interoperability of Smart Grids. IEEE Commun. Mag. 2017, 55, 204-210. [CrossRef] 
3. Britton, J.P.; deVos, A.N. CIM-Based Standards and CIM Evolution. IEEE Trans. Power Syst. 2005, 20, 758-764. [CrossRef]

4. Becker, D.; Saxton, T.L. CIM Standard for Model Exchange between Planning and Operations. In Proceedings of the 2008 IEEE Power and Energy Society General Meeting-Conversion and Delivery of Electrical Energy in the 21st Century, Pittsburgh, PA, USA, 20-24 July 2008. [CrossRef]

5. Becker, D.; Falk, H.; Gillerman, J.; Mauser, S.; Podmore, R.; Schneberger, L. Standards-Based Approach Integrates Utility Applications. IEEE Comput. Appl. Power 2000, 13, 13-20. [CrossRef]

6. Gray, G.R.; Simmins, J.; Rajappan, G.; Ravikumar, G.; Khaparde, S.A. Making Distribution Automation Work: Smart Data Is Imperative for Growth. IEEE Power Energy Mag. 2016, 14, 58-67. [CrossRef]

7. Mânicuță, O. Aspects of Adopting CIM Standard by ENTSO-E and Common Grid Model Exchange Standard Implemention in Transelectrica. J. Energy Power Eng. 2015, 9. [CrossRef]

8. Haq, E.; Wang, X.; Hu, S.X.K.; Colmer, K.; Hunter, K.; Iverson, B.; Garton, H. Application of CIM Extension Principles and Guidelines in Modeling CAISO Market System. In Proceedings of the 2008 IEEE Power and Energy Society General Meeting-Conversion and Delivery of Electrical Energy in the 21st Century, Pittsburgh, PA, USA, 20-24 July 2008. [CrossRef]

9. Haq, E.; Haller, D.; Rodriguez, E. Use of CIM Standard in Power System Modeling \& amp; Enterprise Wide Messaging at California ISO. In Proceedings of the IEEE PES General Meeting, Minneapolis, MN, USA, 25-29 July 2010. [CrossRef]

10. Haq, E.; Haller, D.; Rahman, K.A.; Iverson, B. Use of Common Information Model (CIM) in Electricity Market at California ISO. In Proceedings of the 2011 IEEE Power and Energy Society General Meeting, Detroit, MI, USA, 24-28 July 2011. [CrossRef]

11. Perumalla, V.; Jacobsen, B.; Zulkader, S. Challenges, Solutions and Lessons Learned for Centralized Model Management at California ISO. In Proceedings of the 2017 IEEE Power \& Energy Society General Meeting, Chicago, IL, USA, 16-20 July 2017. [CrossRef]

12. Fremont, J.; Lambert, E.; Bouquet, C.; Carre, O.; Ilhat, D.; Metayer, P. CIM Extensions for ERDF Information System Projects. In Proceedings of the 2009 IEEE Power \& Energy Society General Meeting, Calgary, AB, Canada, 26-30 July 2009. [CrossRef]

13. Chen, D. Framework for Enterprise Interoperability and Maturity Model (CEN/ISO 11354). In Interoperability for Enterprise Software and Applications; John Wiley \& Sons, Inc.: Hoboken, NJ, USA, 2013; pp. 15-22. [CrossRef]

14. Zacharewicz, G.; Diallo, S.; Ducq, Y.; Agostinho, C.; Jardim-Goncalves, R.; Bazoun, H.; Wang, Z.; Doumeingts, G. Model-Based Approaches for Interoperability of next Generation Enterprise Information Systems: State of the Art and Future Challenges. Inf. Syst. e-Bus. Manag. 2016, 15, 229-256. [CrossRef]

15. Uslar, M.; Rohjans, S.; Specht, M.; Vazquez, J.M.G. What Is the CIM Lacking? In Proceedings of the 2010 IEEE PES Innovative Smart Grid Technologies Conference Europe (ISGT Europe), Gothenberg, Sweden, 11-13 October 2010. [CrossRef]

16. International Electrotechnical Commission. IEC 61970, Energy Management System Application Program Interface (EMS-API) part 301: Common Information Model (CIM) Base ed 6.0; International Electrotechnical Commission: Geneva, Switzerland, 2016.

17. King, L. The Common Information Model for Distribution-An Introduction to the CIM for Integrating Distribution Applications and Systems, 1016058; Electric Power Research Institute (EPRI): Palo Alto, CA, USA, 2008.

18. Gray, G. Common Information Model Primer, 5th ed.; Electric Power Research Institute (EPRI): Palo Alto, CA, USA, 2019.

19. National Institute of Standards and Technology. NIST Framework and Roadmap for Smart Grid Interoperability Standards, Release 1.0; National Institute of Standards and Technology: Gaithersburg, MD, USA, 2010. [CrossRef]

20. Ling, L.; Hongyong, Y.; Xia, C. Model Differences between IEC 61970/61968 and IEC 61850. In Proceedings of the 2013 Third International Conference on Intelligent System Design and Engineering Applications, Hong Kong, China, 16-18 January 2013. [CrossRef]

21. Hughes, J. Harmonization of IEC 61970, 61968, and 61850 Models; Electric Power Research Institute (EPRI): Palo Alto, CA, USA, 2006.

22. Becker, D. Harmonizing the International Electrotechnical Commission Common Information Model (CIM) and 61850; Electric Power Research Institute (EPRI): Palo Alto, CA, USA, 2010. 
23. International Electrotechnical Commission. IEC 61968, Application Integration at Electric Utilities-System Interfaces for Distribution Management-Part 14: MultiSpeak-CIM Harmonization ed 1.0; International Electrotechnical Commission: Geneva, Switzerland, 2015.

24. International Electrotechnical Commission. IEC/TS 62361, Power Systems Management and Associated Information Exchange-Interoperability in the Long Term-PART 102: CIM-IEC 61850 Harmonization ed 1.0; International Electrotechnical Commission: Geneva, Switzerland, 2018.

25. Ravikumar, G.; Khaparde, S.A.; Joshi, R.K. The Role of Viewpoints in CIM Profile Projection. In Proceedings of the 2014 IEEE PES General Meeting|Conference \& Exposition, National Harbor, MD, USA, 27-31 July 2014. [CrossRef]

26. Yang, Y.; Liu, D.; Lu, Y.; Gu, J. The Validation of Message Specifications Based on Iec 61968 Standards. In Proceedings of the 2012 China International Conference on Electricity Distribution, Shanghai, China, 29 April 2013. [CrossRef]

27. Fiaschetti, L.; Antunez, M.; Trapani, E.; Valenzuela, L.; Rubiales, A.; Risso, M.; Boroni, G. Monitoring and Controlling Energy Distribution: Implementation of a Distribution Management System Based on Common Information Model. Int. J. Electr. Power Energy Syst. 2018, 94, 67-76. [CrossRef]

28. Popovic, D.S.; Varga, E.; Perlic, Z. Extension of the Common Information Model with a Catalog of Topologies. IEEE Trans. Power Syst. 2007, 22, 770-777. [CrossRef]

29. Lendak, I.I.; Erdeljan, A.M.; Popović, D.S. Algorithm for Cataloging Topologies in the Common Information Model (CIM). Comput. Math. Appl. 2011, 61, 715-721. [CrossRef]

30. Pradeep, Y.; Seshuraju, P.; Khaparde, S.A.; Joshi, R.K. CIM-Based Connectivity Model for Bus-Branch Topology Extraction and Exchange. IEEE Trans. Smart Grid 2011, 2, 244-253. [CrossRef]

31. HUANG, J.; XU, X.; LI, X.; WANG, C. Island Partition in Active Distribution Network Based on CIM. In Proceedings of the 2017 International Conference on Electronic Industry and Automation (EIA 2017), Suzhou, China, 23-25 June 2017; Atlantis Press: Paris, French, 2017. [CrossRef]

32. Sun, H.; Zhang, B.; Wu, W. Applications and Extension of CIM Standard in Chinese Electrical Power Control Centers. In Proceedings of the 2009 IEEE Power \& Energy Society General Meeting, Calgary, AB, Canada, 26-30 July 2009. [CrossRef]

33. Khare, R.; Khadem, M.; Moorty, S.; Methaprayoon, K.; Zhu, J. Patterns and Practices for CIM Applications. In Proceedings of the 2011 IEEE Power and Energy Society General Meeting, Detroit, MI, USA, 24-28 July 2011. [CrossRef]

34. Seo, I.-Y.; Ha, B.-N.; Kim, S.-O.; Heo, K.-U.; Lee, H.-J. CIM Model Extension for Intelligent DAS of Smart Power Grid in Korea. J. Energy Power Eng. 2012, 6. [CrossRef]

35. Xu, K.-N.; Cheng, X.-G.; Xu, X.-J.; Chong, Y.-S. Model Design of Electric System State Estimation Based on CIM. In Proceedings of the 2009 Asia-Pacific Power and Energy Engineering Conference, Wuhan, China, 28-31 March 2009. [CrossRef]

36. Qin, L.; Li, M.; Wang, Y.; Hao, C.; Jin, H. CIM-Based Three-Phase State Estimation of Distribution Network. In Proceedings of the 2011 International Conference on Advanced Power System Automation and Protection, Beijing, China, 16-20 October 2011. [CrossRef]

37. International Electrotechnical Commission. IEC 61970, Energy Management System Application Program Interface (EMS-API) part 301: Common Information Model (CIM) Base ed 4.0.; International Electrotechnical Commission: Geneva, Switzerland, 2013.

38. Sharma, A.; Srivastava, S.C.; Chakrabarti, S. An Extension of Common Information Model for Power System Multiarea State Estimation. IEEE Syst. J. 2017, 11, 1692-1701. [CrossRef]

39. Ten, C.-W.; Wuergler, E.; Diehl, H.-J.; Gooi, H.B. Extraction of Geospatial Topology and Graphics for Distribution Automation Framework. IEEE Trans. Power Syst. 2008, 23, 1776-1782. [CrossRef]

40. Ravikumar, G.; Pradeep, Y.; Khaparde, S.A. Graphics Model for Power Systems Using Layouts and Relative Coordinates in CIM Framework. IEEE Trans. Power Syst. 2013, 28, 3906-3915. [CrossRef]

41. Hussain, A.; Aslam, M.; Arif, S.M. A Standards-Based Approach for Auto-Drawing Single Line Diagram of Multivendor Smart Distribution Systems. Int. J. Electr. Power Energy Syst. 2018, 96, 357-367. [CrossRef]

42. Ravikumar, G.; Khaparde, S.A.; Joshi, R.K. Towards CIM Implementation Challenges in Control Centers Worldwide and Indian Power Grid. In Proceedings of the 2014 Annual IEEE India Conference (INDICON), Pune, India, 11-14 December 2014. [CrossRef] 
43. Ravikumar, G.; Ramya, G.; Khaparde, S.A. CIM Compliant Power System Model Exchange for Indian Power Grid Control Centers. In Proceedings of the 2016 IEEE 6th International Conference on Power Systems (ICPS), Delhi, India, 4-6 March 2016. [CrossRef]

44. Moseley, J.D.; Mago, N.V.; Sarma, N.D.R.; Grady, W.M.; Santoso, S. Extending CIM Standards to Support Exchange of Ratings on Dynamically Rated Equipment. IEEE Trans. Power Syst. 2016, 31, 296-303. [CrossRef]

45. Cheng, Y.; Zhou, Y. A CIM Extended Power Transmission and Transformation on-Line Monitoring System Model. In Proceedings of the 2016 7th IEEE International Conference on Software Engineering and Service Science (ICSESS); IEEE: Piscataway, NJ, USA, 2016. [CrossRef]

46. Chandramohan, L.S.; Ravikumar, G.; Doolla, S.; Khaparde, S.A. Business Process Model for Deriving CIM Profile: A Case Study for Indian Utility. IEEE Trans. Power Syst. 2015, 30, 132-141. [CrossRef]

47. Ravikumar, G.; Khaparde, S.A.; Joshi, R.K. Integration of Process Model and CIM to Represent Events and Chronology in Power System Processes. IEEE Syst. J. 2018, 12, 149-160. [CrossRef]

48. Ding, M.; Zhang, Z.; Guo, X. CIM Extension of Microgrid Energy Management System. In Proceedings of the 2009 Asia-Pacific Power and Energy Engineering Conference, Wuhan, China, 28-31 March 2009. [CrossRef]

49. Hargreaves, N.; Taylor, G.; Carter, A. Smart Grid Interoperability Use Cases for Extending Electricity Storage Modeling within the IEC Common Information Model. In Proceedings of the 2012 47th International Universities Power Engineering Conference (UPEC), London, UK, 4-7 September 2012. [CrossRef]

50. Zhao, L.; Liu, J. Study of Information Integration Architecture Based on the Extensibility of Smart Gird Cim Model. In CIRED Workshop 2016; Institution of Engineering and Technology: London, UK, 2016. [CrossRef]

51. Huang, Y.; Zhang, D.; Lin, J.; Liu, D. Common Information Model Expansion for Distributed Wind Power. In Proceedings of the 2015 International Power, Electronics and Materials Engineering Conference; Atlantis Press: Paris, France, 2015. [CrossRef]

52. Vukmirovic, S.; Erdeljan, A.; Lendak, I.; Čapko, D. Extension of the Common Information Model with Virtual Meter. Elektronika Elektrotechnika 2011, 107, 59-64.

53. International Electrotechnical Commission. IEC 61968, Application Integration at Electric Utilities-System Interfaces for Distribution Management-Part 11: Common Information Model (CIM) Extensions for Distribution ed 2.0; International Electrotechnical Commission: Geneva, Switzerland, 2013.

54. Balijepalli, V.S.K.M.; Khaparde, S.A. Enablement of Consumer-Oriented Interoperable Systems with Integration of CIM and Green Button Standards. IEEE Syst. J. 2013, 7, 681-691. [CrossRef]

55. Mifang, Y.; Wei, T.; Chunhua, Y.; Yang, C. A Study on IEC CIM DR Information Modeling Based on Reverse Engineering. In Proceedings of the 2016 China International Conference on Electricity Distribution (CICED), Xi'an, China, 10-13 August 2016. [CrossRef]

56. Wang, X.; Schulz, N.N.; Neumann, S. CIM Extensions to Electrical Distribution and CIM XML for the IEEE Radial Test Feeders. IEEE Trans. Power Syst. 2003, 18, 1021-1028. [CrossRef]

57. McMorran, A.W.; Ault, G.W.; Morgan, C.; Elders, I.M.; McDonald, J.R. A Common Information Model (CIM) Toolkit Framework Implemented in Java. IEEE Trans. Power Syst. 2006, 21, 194-201. [CrossRef]

58. King, T.L.; McGranaghan, M.F. Using and Extending the CIM Standards for Advanced Distribution Applications. In Proceedings of the 2008 IEEE Power and Energy Society General Meeting-Conversion and Delivery of Electrical Energy in the 21st Century, Pittsburgh, PA, USA, 20-24 July 2008. [CrossRef]

59. Ilich, P.R.; Riddles, R.; Haak, W.; Frowd, R. Application of CIM Model for Enterprise Wide Power System Model for Planning, Protection and Operations. In Proceedings of the 2008 IEEE Power and Energy Society General Meeting-Conversion and Delivery of Electrical Energy in the 21st Century, Pittsburgh, PA, USA, 20-24 July 2008. [CrossRef]

60. Zhang, S.; Zhang, L.; Shao, Z.; Liu, H.; Li, J. Research of Information Model for Power Distribution Equipment Status Management and Control. In Proceedings of the 2015 3rd International Conference on Machinery, Materials and Information Technology Applications, Qingdao, China, 28-29 November 2015. [CrossRef]

61. Yiming, L.; Chen, S.; Guangxian, L.; Peng, J.; Xueyuan, S. Information Modeling of Distribution Grid's Operation Situation under Disastrous Condition and Its Application. In Proceedings of the 2016 China International Conference on Electricity Distribution (CICED), Xi'an, China, 10-13 August 2016. [CrossRef]

62. Burger, E.; Mittelbach, V.; Koziolek, A. View-based and Model-driven Outage Management for the Smart Grid. In Proceedings of the 11th International Workshop on Models@run.Time, Genova, Italy, 15 April 2016. 
63. Greer, C.; Wollman, D.A.; Prochaska, D.E.; Boynton, P.A.; Mazer, J.A.; Nguyen, C.T.; FitzPatrick, G.J.; Nelson, T.L.; Koepke, G.H.; Hefner, A.R., Jr.; et al. NIST Framework and Roadmap for Smart Grid Interoperability Standards, Release 3.0; National Institute of Standards and Technology: Gaithersburg, MD, USA, 2014. [CrossRef]

64. Nieves, J.C.; de Mues, M.O.; Espinoza, A.; Rodriguez-Alvarez, D. Harmonization of Semantic Data Models of Electric Data Standards. In Proceedings of the 2011 9th IEEE International Conference on Industrial Informatics Lisbon, Lisbon, Portugal, 26-29 July 2011. [CrossRef]

65. Kostic, T.; Frei, C.; Preiss, O.; Kezunovic, M. Scenarios for data exchange using standards IEC 61970 and IEC 61850. In Proceedings of the UCA User Group Meeting, Montreal, QC, Canada, 7-9 May 2004.

66. Pradeep, Y.; Seshuraju, P.; Khaparde, S.A.; Warrier, V.S.; Cherian, S. CIM and IEC 61850 Integration Issues: Application to Power Systems. In Proceedings of the 2009 IEEE Power \& Energy Society General Meeting, Alberta, AB, Canada, Alberta 26-30 July 2009. [CrossRef]

67. Choi, J.; Jang, H.; Kim, S. Integration Method Analysis between IEC 61850 and IEC 61970 for Substation Automation System. In Proceedings of the 2009 Transmission \& Distribution Conference \& Exposition: Asia and Pacific, Seoul, Korea, 26-30 October 2009. [CrossRef]

68. Naumann, A.; Bielchev, I.; Voropai, N.; Styczynski, Z. Smart Grid Automation Using IEC 61850 and CIM Standards. Control Eng. Pr. 2014, 25, 102-111. [CrossRef]

69. Santodomingo, R.; Rodriguez-Mondejar, J.A.; Sanz-Bobi, M.A. Ontology Matching Approach to the Harmonization of CIM and IEC 61850 Standards. In Proceedings of the 2010 First IEEE International Conference on Smart Grid Communications, Gaithersburg, MD, USA, 4-6 October 2010.

70. Santodomingo, R.; Rodriguez-Mondejar, J.A.; Sanz-Bobi, M.A.; Rohjans, S.; Uslar, M. Towards the Automatic Alignment of CIM and SCL Ontologies. In Proceedings of the 2011 IEEE International Conference on Smart Grid Communications (SmartGridComm), Brussels, Belgium, 17-20 October 2011. [CrossRef]

71. Santodomingo, R.; Rodriguez-Mondejar, J.A.; Sanz-Bobi, M.A. Using Semantic Web Resources to Translate Existing Files between CIM and IEC 61850. IEEE Trans. Power Syst. 2012, 27, 2047-2054. [CrossRef]

72. Santodomingo, R.; Rohjans, S.; Uslar, M.; Rodriguez-Mondejar, J.A.; Sanz-Bobi, M.A. Facilitating the Automatic Mapping of IEC 61850 Signals and CIM Measurements. IEEE Trans. Power Syst. 2013, 28, 4348-4355. [CrossRef]

73. Zhang, S.; Shi, L.; Wang, B. A Conversion Method for SCL to CIM Based on Ontology Matching. In Proceedings of the 2015 3rd International Conference on Machinery, Materials and Information Technology Applications, Qingdao, China, 28-29 November 2015. [CrossRef]

74. Kim, J.-S.; So, S.M.; Kim, J.-T.; Cho, J.-W.; Park, H.-J.; Jufri, F.H.; Jung, J. Microgrids Platform: A Design and Implementation of Common Platform for Seamless Microgrids Operation. Electr. Power Syst. Res. 2019, 167, 21-38. [CrossRef]

75. Kostic, T.; Preiss, O.; Frei, C. Towards the Formal Integration of Two Upcoming Standards: IEC 61970 and IEC 61850. In Proceedings of the Large Engineering Systems Conference on Power Engineering, Montréal, QC, Canada, 7-9 May 2003. [CrossRef]

76. Preiss, O.; Kostic, T. Unified Information Models in Support of Location Transparency for Future Utility Applications. In Proceedings of the 39th Annual Hawaii International Conference on System Sciences (HICSS’06), Kauai, HI, USA, 4-7 January 2006. [CrossRef]

77. Mercurio, A.; Di Giorgio, A.; Cioci, P. Open-Source Implementation of Monitoring and Controlling Services for EMS/SCADA Systems by Means of Web Services_IEC 61850 and IEC 61970 Standards. IEEE Trans. Power Deliv. 2009, 24, 1148-1153. [CrossRef]

78. Dutta, P.; Kezunovic, M. Unified Representation of Data and Model for Sparse Measurement Based Fault Location. In Proceedings of the 2012 IEEE Power and Energy Society General Meeting, San Diego, CA, USA, 22-26 July 2012. [CrossRef]

79. Sun, H.; Chen, R.; Guo, Q.; Wang, J.; Zhang, Y.; Wu, W.; Zhang, B. A Two-Level Distributed Approach to Power Network Modeling. IEEE Trans. Power Deliv. 2015, 30, 1496-1504. [CrossRef]

80. Pei, W.; Qi, Z.; Deng, W.; Shen, Z. Operation of Battery Energy Storage System Using Extensional Information Model Based on IEC 61850 for Micro-Grids. IET Gener. Transm. Distrib. 2016, 10, 849-861. [CrossRef]

81. ICF (2016). Standards and Interoperability in Electric Distribution Systems. Available online: https://www.energy.gov/sites/prod/files/2017/01/f34/Standards\%20and\%20Interoperability\%20in\% 20Electric\%20Distribution\%20Systems.pdf (accessed on 2 February 2020). 
82. Schumilin, A.; Stucky, K.-U.; Sinn, F.; Hagenmeyer, V. Towards Ontology-Based Network Model Management and Data Integration for Smart Grids. In Proceedings of the 2017 Workshop on Modeling and Simulation of Cyber-Physical Energy Systems (MSCPES), Pittsburgh, PA, USA, 21 April 2017. [CrossRef]

83. Schumilin, A.; Duepmeier, C.; Stucky, K.-U.; Hagenmeyer, V. A Consistent View of the Smart Grid: Bridging the Gap between IEC CIM and IEC 61850. In Proceedings of the 2018 44th Euromicro Conference on Software Engineering and Advanced Applications (SEAA), Prague, Czech, 29-31 August 2018. [CrossRef]

84. Alaerjan, A.; Kim, D.-K.; Ming, H.; Malik, K. Using DDS Based on Unified Data Model to Improve Interoperability of Smart Grids. In Proceedings of the 2018 IEEE International Conference on Smart Energy Grid Engineering (SEGE), UOIT, ON, Canada, 12 August 2018. [CrossRef]

85. Dae-Kyoo, K.; Yang, H.; Jang, H.; Hong, D.; Falk, H.; Kim, S.; Lee, B. A Metamodeling Approach to Unifying IEC 61850 and IEC 61970. In Proceedings of the 2013 IEEE PES Innovative Smart Grid Technologies Conference (ISGT), Washington, DC, USA, 19-22 February 2013. [CrossRef]

86. Kim, D.-K.; Lee, B.; Kim, S.; Yang, H.; Jang, H.; Hong, D.; Falk, H. QVT-Based Model Transformation to Support Unification of IEC 61850 and IEC 61970. EEE Trans. Power Deliv. 2014, 29, 598-606. [CrossRef]

87. Lee, B.; Kim, D.-K.; Yang, H.; Jang, H.; Hong, D.; Falk, H. Unifying Data Types of IEC 61850 and CIM. IEEE Trans. Power Syst. 2015, 30, 448-456. [CrossRef]

88. Lee, B.; Kim, D.-K. Harmonizing IEC 61850 and CIM for Connectivity of Substation Automation. Comput. Stand. Interfacess 2017, 50, 199-208. [CrossRef]

89. Jiaan, Z.; Tao, X.; Wei, L.; Sheng, X.; Lingxu, G.; Zhigang, H.; Guangmin, F. A Cooperative Modeling Scheme between Power Transformer Substation and Control Center. In Proceedings of the 2014 4th IEEE International Conference on Information Science and Technology, Shenzhen, China, 26-28 April 2014. [CrossRef]

90. Huang, G.M.; Nair, N.-K.C. Static and Dynamic CIM-XML Documents for Proprietary EMS. In Proceedings of the 2003 IEEE Power Engineering Society General Meeting (IEEE Cat. No.03CH37491), Toronto, ON, Canada, 13-17 July 2003. [CrossRef]

91. Deng, C.; Liu, Y.; Xu, L.; Yang, J.; Liu, J.; Li, S.; Li, M. A MapReduce-Based parallelK-Meansclustering for Large-Scale CIM Data Verification. Concurr. Comput. Pr. Exp. 2015, 28, 3096-3114. [CrossRef]

92. Hallé, S.; Deca, R.; Cherkaoui, O.; Villemaire, R.; Puche, D. A Formal Validation Model for the Netconf Protocol. In Utility Computing; Springer: Berlin/Heidelberg, Germany, 2004. [CrossRef]

93. Zhang, H.; Huang, H.F.; Zhu, G.Y. Key Technologies Research of the Interoperable Model Verification Based on CIM/E. Appl. Mech. Mater. 2013, 411-414, 1826-1830. [CrossRef]

94. Dangi, S.; Ray, S.; Hodgson, R.; Soydan, G.; Oberai, A. Using sparql/owl for validation of smart grid standards. In Proceedings of the Grid-Interop Forum, Irving, TX, USA, 3-6 December 2012.

95. Tomaszuk, D. RDF Validation: A Brief Survey. In International Conference: Beyond Databases, Architectures and Structures; Springer: Cham, Switzerland, 2017; pp. 344-355. [CrossRef]

96. Nenadic, K.R.; Gavric, M.M.; Durdevic, V.I. Validation of CIM Datasets Using SHACL. In Proceedings of the 2017 25th Telecommunication Forum (TELFOR), Belgrade, Serbia, 21-22 November 2017. [CrossRef]

97. Marcadet, D.; Lambert, E. RiseClipse: Why Working at the Model Level Is Better for Validating Data Conforming to IEC Standards. In Proceedings of the 2016 Power Systems Computation Conference (PSCC), Genoa, Italy, 20-24 June 2016. [CrossRef]

98. Jang, B.T.; Alidu, A.; Kim, N.D. Design of an Algorithm for the Validation of SCL in Digital Substations. KEPCO J. Electr. Power Energy 2017, 3, 89-97. [CrossRef]

99. Jang, B.; Abubakari, A.; Kim, N. IEC 61850 SCL Validation Using UML Model in Modern Digital Substation. Smart Grid Renew. Energy 2018, 9, 127-149. [CrossRef]

(C) 2020 by the authors. Licensee MDPI, Basel, Switzerland. This article is an open access article distributed under the terms and conditions of the Creative Commons Attribution (CC BY) license (http://creativecommons.org/licenses/by/4.0/). 